\title{
Do social comparisons in academic settings relate to gender and academic self-confidence?
}

\author{
Briony D. Pulford ${ }^{1}$ (D) Bethan Woodward ${ }^{1} \cdot$ Eve Taylor $^{1}$
}

Received: 28 February 2017/Accepted: 6 February 2018/Published online: 7 March 2018

(C) The Author(s) 2018. This article is an open access publication

\begin{abstract}
This paper reports the development of an Academic Social Comparison Scale (ASCS) to measure students' tendencies to socially compare themselves with other students in an educational setting. The 27-item ASCS was then measured in relation to academic self-confidence in a sample of University students, using the Individual Learning Profile (ILP) scale. The study found that making downward academic social comparisons was not very commonly reported and did not relate to academic confidence in any domain measured. Confidence in numeracy, speaking, and hard IT were, however, significantly lower in those students who tended to make more upward social comparisons. The results also showed that the less students reported that they socially compared in general, the more confident they were in reading, writing, and time management. All three subscales of the ASCS showed good reliability when tested 6-9 weeks later. The ASCS showed that female students tended to make more upward academic social comparisons and less downward academic comparisons than male students. In domains such as reading and writing people's confidence was higher if they made fewer academic social comparisons (irrespective of direction), and gender was not an important factor. Results also showed that academic confidence was neither higher nor lower in students who reported making more downwards academic comparisons. This study demonstrates the negative impact on confidence of upward social comparisons, and introduces a
\end{abstract}

Briony D. Pulford

bdp5@le.ac.uk

Bethan Woodward

bethwood823@hotmail.com

Eve Taylor

eviolettaylor@gmail.com

1 Department of Neuroscience, Psychology and Behaviour, University of Leicester, University

Road, Leicester LE1 7RH, UK 
social comparison questionnaire specifically tailored for measuring people's tendencies to make social comparisons in the academic domain.

Keywords Social comparison - Individual learning profile $\cdot$ Academic confidence $\cdot$ Scale development

\section{Introduction}

Academic success is rarely attributed to ability alone. People have to be motivated to study and the effort that they put in plays a big role in achievements. Higher selfconfidence can be a driving force, motivating people to act and persist. Conversely, low self-confidence and illusory inferiority can result in slower progress or even dropping out of studying (Wehrens 2008). The role of confidence, in terms of the perception of our own abilities, has been shown to have a positive effect on incentive and motivation (Benabou and Tirole 2002). Chemers et al. (2001) found that for university students, self-confidence in their academic abilities was not only significantly related to expectations of success, it also positively affected their academic performance. Academic confidence has an important impact on students' desire to learn more in the future; and those with low confidence are not only less motivated in their current education, but are less likely to consider further education (Ireson and Hallam 2009).

\subsection{Desire to socially compare}

Students typically work alongside other students on similar or identical tasks and receive feedback about their performance. Such a situation almost inevitably fosters a desire in those students to socially compare their own performance with other students' performance. Social comparison theory (Festinger 1954) explains how the way in which we perceive the abilities of others can in turn affect the perception of our own abilities, impacting on self-confidence. Sander and Sanders (2006) stress the importance of social processes in academic self-confidence. Students belong to different social communities and consider their own capabilities in comparison to other students in that community. These comparisons are often unavoidable as the learning experience is not a solitary process; students have to attend classes with other students and are therefore constantly exposed to the progress of their peers, with comparison between friends now becoming the norm (Mussweiler et al. 2004). As Mussweiler et al. have shown, social comparisons are ubiquitous and occur spontaneously, even if the target being compared with only appears for a fleetingly short time. For an excellent synthesis of the topic of social comparison see Buunk and Gibbons (2007).

\subsection{Social comparison and academic achievement}

Research has focused on both upward (with a more capable person) and downward (with a less capable person) comparisons. In an extensive study lasting two years, 
Wehrens et al. (2010) showed that in $95 \%$ of cases students socially compared with a student of the same gender. They also concluded "that that the more upward or the less downward students compared themselves, the higher their academic performance was 2 years later, as indicated by their test scores for reading comprehension and mathematics" (p. 1168). Wehrens et al. asked students to name one classmate they preferred to compare grades to, and $60 \%$ did this, while $12 \%$ declared they did not compare grades and $28 \%$ did not answer. Our study takes a broader view to quantify the degree to which students socially compare and the comparison direction that they tend to take.

Furthermore, Blanton et al. (1999) studied social comparison in high-school students and found that grades were higher if students had made an upward social comparison rather than a downwards one. Blanton et al. proposed that seeing a competent person can provide information on how to improve one's own performance. This was echoed in the study by Wehrens et al. (2010), who argued that for upwards social comparisons to be motivating the higher level of performance has to seem attainable, and that requires a degree of self-confidence.

\subsection{Social comparisons and self-confidence}

The way that students feel about their abilities is not solely determined by their abilities, as evidenced by the fact that students of equal abilities in different settings (low-ability versus high-ability schools) have different levels of academic selfconcept. This "Big-Fish-Little-Pond" effect (Marsh 1991), has been shown to be driven by social comparisons (Huguet et al. 2009). The relationship between social comparison and academic confidence has been demonstrated in a number of different educational areas and academic settings. For example, perceived standing, both of the student and the school, has been shown to positively associate with confidence in mathematical ability (Trautwein et al. 2009). Self-concept in the mathematical domain was also studied in three studies by Müller-Kalthoff et al. (2017) who investigated the joint effects of social, temporal, and dimensional comparisons and concluded that they have independent and additive effects on academic self-concept. In their third study, that studied high-school children, it was social comparison, not temporal or dimensional, that had the largest impact on the children's reported mathematical self-concept. As well as influencing self-concept, social comparisons can also increase academic performance, in children at least, by increasing self-perceptions of competence by making downwards social comparisons (Guay et al. 1999).

In a recent meta-analysis by Braithwaite and Corr (2016), the factors that enhance self-efficacy and self-confidence were examined in relation to academic achievement in higher education students. They conclude that individual difference variables are important in educational design and need further study. Individual differences, especially confidence, have been shown to be a strong predictor of students' achievement in subjects such as English and maths (Stankov et al. 2012). As Stankov et al. point out, non-cognitive variables are important in and of themselves, and if interventions can raise things like confidence then academic performance may similarly increase. 


\subsection{Gender differences}

The impact of the gender of the student has arisen as a factor that may influence both academic confidence and social comparison processes. Michie et al. (2001) found that women are more likely to report larger amounts of academic stress than men, and also that women often have less confidence in their educational abilities than men. Gender differences have also been found in the effect of social comparison on academic confidence. When making upward comparisons to those individuals who are viewed as superior, women were more likely to report lower confidence than men (Locke 2005), which implies that women are more likely to let social factors influence their perception of their own academic abilities.

\subsection{Current research}

This study aims to discover how social comparison in the educational setting of a university affects the self-confidence of students in their self-perceptions of ability in different areas of their course. Previous literature indicates that social comparison is of significance in academic achievement and confidence. However, there is a lack of research on comparisons that take place in the different academic domains. Recognition of social comparison orientation as an individual difference lead to the development of a scale to measure it in general (SCO; Gibbons and Buunk 1999). As there is currently no good measure of assessing social comparison in academic domains, we developed and validated a new scale to specifically measure how much, and in what direction, people socially compare in academic settings.

We chose to use the ILP (Pulford and Sohal 2006) to measure confidence in academic ability. The ILP does not measure the same as the ABC (Academic Behavioural Confidence) scale. The ABC (Sander and Sanders 2006, 2009) measures "the confidence that undergraduate university students have in their own anticipated study behaviours in relation to their degree programme" (p. 19). The $\mathrm{ABC}$ thus focusses on students' judgements of their future efficacy in getting good grades, verbally communicating, studying, and attending classes. The ILP measures current confidence in academic abilities in six specific domains.

Academic confidence has been found to be affected by the direction of the comparison, so the study aims to look at how upward and downward social comparisons individually affect confidence in education. The issue of the gender of the student has also been demonstrated to affect both confidence and social comparison processes in education, so this will be further investigated. It is predicted that social comparison in academic areas will relate to academic confidence and that gender and the direction of the comparison will influence the effect. 


\section{Method}

\subsection{Participants}

The sample consisted of 325 Psychology students (80 men and 245 women) from the University of Leicester in the UK, aged between 18 and 44 years old, $(M=20.01, S D=3.16)$, who volunteered to complete the ASCS for course credits. Of these participants 253 also volunteered to complete the ILP scale. Thirty-six of the participants completed the ASCS a second time, 6-9 weeks later, for reliability purposes.

\subsection{Design}

A questionnaire was employed to measure both academic confidence and social comparison in an academic setting. The Individual Learning Profile (ILP) (Pulford and Sohal 2006) measured academic confidence. The Academic Social Comparison Scale (ASCS), created for this study, measured how much students academically compared themselves with other students.

\subsection{Materials and procedure}

The ASCS was developed for this study using the stages demonstrated in developing a general social comparison questionnaire by Gibbons and Buunk (1999). This was adapted for the purpose of this study to give an understanding of social comparison in an academic setting, using the ILP as a basis for the different educational areas. The initial ASCS included 48 questions assessing tendency to socially compare with other students in each of several academic areas and situations. For each academic area, both an upward and a downward comparison was included, assessing if participants compare themselves with higher-achieving students and lower-achieving students. A general statement was also included for each academic area which measured if students compared themselves academically or not. Participants answered on a seven-point scale from 1 'strongly disagree' to 7 'strongly agree'. The ILP contained 40 questions with five academic sub-scales assessing confidence in: speaking, numeracy, reading and writing, time management, and IT skills, responding on a four-point scale. Participants provided informed consent. The demographics, ASCS and ILP were counterbalanced, and with items in randomly presented order. Participants were debriefed. All data were anonymous and confidential. Ethical approval was granted by the University ethics committee to meet APA and BPS standards.

\subsection{Data analysis}

The scores from ordinal scales were considered as interval data for the statistical tests and for reporting purposes. All of the statistical tests were reported at a twotailed level of significance and the alpha level was set at .05. The mean score for 
each subscale was computed at times 1 and 2. No variables or data points were excluded from analyses.

\section{Results}

\subsection{Factor analysis}

Initially, the factorability of the 48 ASCS items was examined. The Kaiser-MeyerOlkin sampling adequacy was .94, above the recommended value of .6, and Bartlett's test of sphericity was significant $\chi^{2}(1128)=8306.55, p<.001$. Three main factors were extracted: Downward Social Comparison (31.06\% of variance); Upward Social Comparison (11.05\% of variance); and No Social Comparison (4.18\% of variance), which accounted for $46.30 \%$ of the variance. After removal of some items to improve reliability the Cronbach alpha for Downward Social Comparison was 0.93 (10 items), Upward Social Comparison alpha $=0.91$ (10 items), and No Social Comparison alpha $=0.92$ ( 7 items). The final 27 items are displayed in Table 1.

There were intercorrelations between the three factors. People who made more downwards social comparisons also tended to make more upwards social comparisons $(r=.381, N=325, p<.001)$. People who reported tending not to make social comparisons were consistent and thus reported making fewer downward comparisons $(r=-.445, N=325, p<.001)$ and fewer upward comparisons $(r=-.632, N=325, p<.001)$. The patterns of these relationships were similar for men and women. Students tended to report higher levels of Upwards Comparisons $(M=4.54)$ than No Comparisons $(\mathrm{M}=3.96)$ and both of these were significantly higher than the level of Downward Comparisons $(M=3.35), F(2,646)=36.866, p<.001$, partial $\eta^{2}=.102$, power $=1.00$. The mean of 3.35 on the 7-point scale indicated that people tended on average to report disagreeing that they make downward comparisons, whereas the mean of 4.54 indicates that they do agree that they tend to make upward comparisons. Descriptive statistics are shown in Table 2.

\subsection{Temporal stability}

The temporal stability of the ASCS and the ILP was examined with Pearson's Product Moment Correlation, based upon 36 participants who had completed the questionnaires on two separate occasions. Table 2 shows that both scales had good reliability over time.

\subsection{Multiple regressions}

The regressions in Table 3 show that the tendency to make downwards social comparisons is not related to confidence in academic abilities. However, people reporting that they make fewer upward social comparisons have higher confidence in numeracy, speaking, and hard IT. Furthermore, people who make altogether 
Table 1 Items and subscales in the final Academic Social Comparison Scale

\begin{tabular}{llll}
\hline Item & Down & Up & No \\
& SC & SC & SC \\
\hline
\end{tabular}

1 I compare myself to those students who seem less comfortable writing practical reports than me

2 When writing essays, I compare myself to those students who I perceive as weaker at writing them than me

3 I compare myself to those students who I perceive as less able to produce coursework than I am

4 I compare myself to other students who seem less able to carry out statistics than me

5 I compare myself to those students who are less capable of reading and interpreting research than me

6 When using computers, I compare myself to those students weaker at using them than myself

7 I can't help but compare myself to those students who are not as comfortable using SPSS software as me

8 When I am feeling confident and happy with my degree, I compare myself to those students who are doing badly

9 I can't help but compare myself to other students who appear to be weaker than me in group discussions

10 I compare myself to those students who organise their time less efficiently than myself

11 When writing practical reports, I compare myself to those students who seem more at ease than I am

12 I often compare myself to other students who are better at carrying out statistics than me

13 I compare myself to those students who seem more capable of using SPSS software than I am

14 When things are going poorly for me in my degree, I think of other students I know who are doing better than me

15 I evaluate my ability in producing coursework in relation to those students who appear to be better at it than myself

16 I compare myself to those students who appear to be more at ease in writing essays than me

17 I compare myself to those students who appear to be more prepared in exam situations

18 In presentations, I compare myself to other students who have performed better than me

19 I think about how capable I am of reading and interpreting research in relation to those students who are better than me at it

20 I sometimes compare myself to other students who seem more able and at ease in group discussions

21 I do not think about my ability in reading and interpreting research in relation to other students

22 I am not concerned with comparing myself to other students in my ability to meet deadlines

23 I do not compare myself to other students when thinking about how efficiently I organise my time 
Table 1 continued

\begin{tabular}{|c|c|c|c|c|}
\hline & Item & $\begin{array}{l}\text { Down } \\
\text { SC }\end{array}$ & $\begin{array}{l}\text { Up } \\
\text { SC }\end{array}$ & $\begin{array}{l}\text { No } \\
\text { SC }\end{array}$ \\
\hline 24 & $\begin{array}{l}\text { I never consider my ability to produce coursework in relation to other } \\
\text { students }\end{array}$ & & & .539 \\
\hline 25 & $\begin{array}{l}\text { When things are going well in my degree, I do not think to compare myself } \\
\text { with the progress of other students }\end{array}$ & & & .529 \\
\hline 26 & $\begin{array}{l}\text { I don't mind whether other students I study with seem more intelligent or } \\
\text { less intelligent than myself }\end{array}$ & & & .527 \\
\hline 27 & $\begin{array}{l}\text { When writing essays, I don't compare myself to the essay-writing ability of } \\
\text { other students }\end{array}$ & & & .420 \\
\hline
\end{tabular}

This scale can be used with students who do not use SPSS/Statistics by the removal of items 4, 7, 12, and 13 with reliability still high

Table 2 Means, standard deviations, and reliability correlations for all variables

\begin{tabular}{llllll}
\hline & Mean & SD & $95 \%$ CI & N & $\begin{array}{c}\text { Correlation } \\
\text { T1 and T2 }\end{array}$ \\
\hline ASCS & & & & & \\
Down comparison & 3.35 & 1.26 & {$[3.21,3.48]$} & 325 & $.73 * * *$ \\
Up comparison & 4.54 & 1.19 & {$[4.41,4.67]$} & 325 & $.77 * * *$ \\
No comparison & 3.96 & 1.11 & {$[3.84,4.08]$} & 325 & $.73 * * *$ \\
ILP & & & & & 253 \\
Total numeracy & 21.23 & 5.28 & {$[20.58,21.88]$} & 253 & $.76^{* * * *}$ \\
Total read and write & 36.31 & 5.64 & {$[35.61,37.01]$} & 253 \\
Total easy IT & 18.37 & 2.03 & {$[18.12,18.62]$} & 253 & $.59 * * *$ \\
Total speaking & 10.21 & 2.46 & {$[9.91,10.52]$} & 253 & $.73 * * *$ \\
Total time manage & 16.53 & 3.13 & {$[16.14,16.91]$} & 253 & $.66 * * *$ \\
Total hard IT & 14.34 & 2.91 & {$[13.98,14.70]$} & 253 & $.79 * * *$ \\
\hline
\end{tabular}

$* * * p<.001$

fewer comparisons have higher confidence in reading and writing and also time management (a low score on No Comparisons indicates that the person does socially compare). Both of these findings suggest that higher confidence is related to making fewer social comparisons. Confidence in easy IT skills was unrelated to social comparisons, possibly because students were generally highly confident in this domain, which they had mastered. Being female (coded 2) predicted lower confidence in numeracy and hard IT but more confidence in time management.

\subsection{Gender differences}

The scores on the Social Comparison scales interacted with gender $F(2$, $646)=5.050, p=.007$, partial $\eta^{2}=.015$, power $=.82$. Table 4 shows that 
Table 3 Multiple regression statistics and standardised beta values of the predictors of academic confidence

\begin{tabular}{lllllll}
\hline Predictors & \multicolumn{7}{l}{ Academic confidence } & & & \\
\cline { 2 - 7 } & Numeracy & Read and write & Easy IT & Speaking & Time manage & Hard IT \\
\hline Constant & 26.203 & 31.459 & 17.723 & 13.044 & 12.039 & 17.792 \\
Adjusted $\mathrm{R}^{2}$ & .058 & .053 & .004 & .084 & .063 & .045 \\
$F$ & $6.195 * * *$ & $14.997 * * *$ & 1.960 & $24.196 * * *$ & $9.508 * * *$ & $6.961^{* * * *}$ \\
Age & n.s. & n.s. & n.s. & n.s. & n.s. & n.s. \\
Gender & $-0.172 * *$ & n.s. & n.s. & n.s. & $0.198^{* *}$ & $-0.174 * *$ \\
Down comparison & n.s. & n.s. & n.s. & n.s. & n.s. & n.s. \\
Up comparison & $-0.158^{*}$ & n.s. & n.s. & $-0.282 * * *$ & n.s. & $-0.129 *$ \\
No comparison & n.s. & $0.237 * * *$ & n.s. & n.s. & $0.180^{* *}$ & n.s. \\
\hline
\end{tabular}

$* p<.05 ; * * p<.01 ; * * * p<.001 ; N=252$

Table 4 Descriptive statistics, $t$, and $\mathrm{d}$ for the Social Comparison Scale and six factors of the individual learning profile (ILP), for male and female students

\begin{tabular}{|c|c|c|c|c|c|c|}
\hline Measure & Gender & Mean & SD & $t$ & $p$ & $\mathrm{~d}$ \\
\hline \multirow[t]{2}{*}{ Downwards comparison } & Male & 3.61 & 1.21 & 2.210 & .028 & 0.28 \\
\hline & Female & 3.26 & 1.26 & & & \\
\hline \multirow[t]{2}{*}{ Upwards comparison } & Male & 4.26 & 1.16 & -2.463 & .014 & -0.31 \\
\hline & Female & 4.63 & 1.17 & & & \\
\hline \multirow[t]{2}{*}{ No comparison } & Male & 4.07 & 1.13 & 1.027 & .305 & 0.13 \\
\hline & Female & 3.92 & 1.10 & & & \\
\hline \multirow[t]{2}{*}{ Numeracy (range 8-32) } & Male & 23.11 & 5.34 & 3.431 & .001 & 0.48 \\
\hline & Female & 20.57 & 5.11 & & & \\
\hline \multirow[t]{2}{*}{ Reading and writing (range 19-48) } & Male & 36.74 & 5.34 & 0.727 & .468 & 0.10 \\
\hline & Female & 36.16 & 5.74 & & & \\
\hline \multirow[t]{2}{*}{ Easy IT (range 8-20) } & Male & 18.42 & 1.98 & 0.244 & .807 & 0.04 \\
\hline & Female & 18.35 & 2.06 & & & \\
\hline \multirow[t]{2}{*}{ Speaking (range 5-16) } & Male & 10.82 & 2.42 & 2.349 & .020 & 0.33 \\
\hline & Female & 10.00 & 2.44 & & & \\
\hline \multirow[t]{2}{*}{ Time management (range 8-24) } & Male & 15.50 & 3.50 & -3.156 & .002 & -0.44 \\
\hline & Female & 16.89 & 2.91 & & & \\
\hline \multirow[t]{2}{*}{ Hard IT (range 7-20) } & Male & 15.27 & 2.61 & 3.082 & .002 & 0.43 \\
\hline & Female & 14.01 & 2.94 & & & \\
\hline
\end{tabular}

ILP (Male: $\mathrm{N}=66$, Female: $\mathrm{N}=187$ ), ASCS (Male: $\mathrm{N}=80$, Female: $\mathrm{N}=245$ )

women had a significantly lower score than men on Downwards Social comparisons, revealing that they were more likely to say that they did not make them. While men and women did not significantly differ in the No Comparison scale, the 
women were significantly higher on the Upwards comparison scale than men, revealing that the women were more likely to agree that they made upwards social comparisons than men in an academic setting.

Independent $t$-tests show significant differences between men and women in ILP scores. Confidence was significantly higher in men than women in numeracy, speaking and hard IT skills. However, women were significantly more confident in time management. There were no significant gender differences for confidence in reading and writing or easy IT.

\section{Discussion}

\subsection{Social comparisons and self-confidence}

As predicted, the tendency to make upwards social comparisons in academic situations correlated with lower academic confidence in several domains, and people who made fewer academic comparisons had higher academic confidence in other domains. Making social comparisons made a difference to confidence in all academic domains other than the easy IT skills, where confidence was already high. A well established skill like easy IT may be resistant to drops in confidence from social comparisons. People who reported that they make fewer upward social comparisons also report having higher confidence in their numeracy, speaking, and hard IT skills. Similarly, those who make altogether fewer comparisons have higher confidence in reading and writing and also time management. In domains such as reading and writing people's confidence was higher if they made fewer social comparisons (irrespective of direction) and gender was not important. However, no relationship concerning downwards comparisons were observed, which was unanticipated.

Our findings concur with those of Müller-Kalthoff et al. (2017) who found lower mathematical self-concept after upward social comparisons. Our findings are also similar to those of Jansen et al. (2015), who found that students compared differently depending on the academic subject and whether it was within or between different domains. This suggests that comparison effects are domain specific and we cannot use academic confidence as a single overall variable.

\subsection{Gender differences}

As predicted, gender differences arose. Women were significantly more likely to make upwards comparisons than men and also reported higher confidence in time management. However, men were significantly more likely to make downwards comparisons than women and were more confident in speaking, numeracy and hard IT. It has been suggested that men and women engage in different social comparisons because of self-stereotyping (Guimond et al. 2007). Therefore, the differences in academic confidence may stem from the stereotype that men are better at numeracy and IT than women, a stereotype that has been shown to be evident in girls as young as 9 (Steffens et al. 2010). Our research agrees with 
Locke's (2005) finding that women who make more upward social comparisons can have lower confidence, as we found that to be true in areas such as numeracy and hard IT skills, which may also be perceived as more masculine domains.

\subsection{Causality concerns}

We have the same concerns as Wehrens et al. (2010) in that the relationship between social comparisons and academic achievement, or in our case confidence, may not be causal in nature. Although it intuitively seems likely that a causal relationship is likely to exist, the data are correlational. To argue a case for a causal direction to the relationship we can turn to the experimental literature. In an experimental study by Strickhouser and Zell (2015), social comparison information was manipulated so that participants were told that they had performed better or worse than other participants, and as a result self-evaluations of performance were directly influenced by social comparisons. Other researchers too have found, using experimental methodologies, that social comparison information causally influences self-evaluations (Fiske 2011; Suls and Wheeler 2000).

Recent research by de Vries and Kühne (2015) has shown that negative selfperceptions can be increased by negative social comparisons (via Facebook use). These authors also acknowledged that causality is difficult to establish, but argue that their explanation is in line with social comparison theory (Festinger 1954). Other recent experimental work has shown the negative impact of social comparisons (via Facebook) on self-perceptions and self-esteem (Vogel et al. 2015), especially for those people who tend to socially compare more frequently (high SCO). Thus there appears to be experimental support as well as theoretical justification for our argument that academic confidence is influenced by social comparisons.

\subsection{Future directions}

In academic social comparisons an upward comparison could potentially increase confidence if the person realises the similarities between the target and themselves (assimilation), and that higher achievement is possible. However, upwards contrasting comparisons (feeling dissimilar to the target) could create feelings of inferiority and reduce academic confidence (Collins 2000). Therefore future research could examine how academic confidence is influenced, not only by direction of comparison but by assimilation and contrast. Jiang and Kleitman (2015) showed that Self-protection and Self-enhancement tendencies predict metacognitive beliefs, which then influence confidence. Our findings may indicate that the tendency to make upward social comparisons may be reducing students' ability to protect and enhance their metacognitive beliefs thus resulting in lower academic confidence, and this also deserves further study.

Studying the relationship between social comparison and academic confidence in older adults would also be of interest, as education carries on across people's lives in one form or another, in different work or educational settings. The tendency to socially compare tends to be higher in younger than older adults, and younger adults 
tend to feel more personal relative deprivation as a consequence of socially comparing (Callan et al. 2015).

\subsection{Conclusions}

Overall we find that many types of academic confidence are negatively impacted by people making upwards comparisons. As Gibbons and Buunk (1999) pointed out, it may be advantageous in some situations to reduce social comparisons and to help people control or alter the direction of them. Most studies in this field are largely non-experimental. Our research findings suggest that a possible intervention study would be a logical next step. If academic self-confidence was measured and then students were taught about social comparisons and encouraged to mentally undo them (by the process of 'decomparing' after upward comparisons, (see Gilbert et al. 1995) then the resulting effect on self-confidence and also academic achievement could be measured and compared with a control group. This is the sort of experimental design advocated by Braithwaite and Corr (2016) that will lead to causally concrete conclusions.

Acknowledgements The authors declare that there are no potential conflicts of interest with respect to the research, authorship, and/or publication of this article. This research did not receive any specific grant from funding agencies in the public, commercial, or not-for-profit sectors. Raw data supporting this article can be retrieved from the Leicester Research Archive.

Open Access This article is distributed under the terms of the Creative Commons Attribution 4.0 International License (http://creativecommons.org/licenses/by/4.0/), which permits unrestricted use, distribution, and reproduction in any medium, provided you give appropriate credit to the original author(s) and the source, provide a link to the Creative Commons license, and indicate if changes were made.

\section{References}

Benabou, R., \& Tirole, J. (2002). Self-confidence and personal motivation. The Quarterly Journal of Economics, 117(3), 871-915. https://doi.org/10.1162/003355302760193913.

Blanton, H., Buunk, B. P., Gibbons, F. X., \& Kuyper, H. (1999). When better-than-others compare upward: Choice of comparison and comparative evaluation as independent predictors of academic performance. Journal of Personality and Social Psychology, 76(3), 420-430. https://doi.org/10. 1037/0022-3514.76.3.420.

Braithwaite, R., \& Corr, P. J. (2016). Hans Eysenck, education and the experimental approach: A metaanalysis of academic capabilities in university students. Personality and Individual Differences, 103, 163-171. https://doi.org/10.1016/j.paid.2016.03.040.

Buunk, B. P., \& Gibbons, F. (2007). Social comparison: The end of a theory and the emergence of a field. Organizational Behavior and Human Decision Processes, 102(1), 3-21. https://doi.org/10.1016/j. obhdp.2006.09.007.

Callan, M. J., Kim, H., \& Matthews, W. J. (2015). Age differences in social comparison tendency and personal relative deprivation. Personality and Individual Differences, 87, 196-199. https://doi.org/ 10.1016/j.paid.2015.08.003.

Chemers, M., Hu, L., \& Garcia, B. F. (2001). Academic self-efficacy and first year college student performance and adjustment. Journal of Educational Psychology, 93(1), 55-64. https://doi.org/10. 1037//0022-0663.93.1.55. 
Collins, R. L. (2000). Among the better ones: Upward assimilation in social comparison. In J. Suls \& L. Wheeler (Eds.), Handbook of social comparison: Theory and research (pp. 159-171). Dordrecht: Kluwer Academic Publishers.

de Vries, D. A., \& Kühne, R. (2015). Facebook and self-perception: Individual susceptibility to negative social comparison on Facebook. Personality and Individual Differences, 86, 217-221. https://doi. org/10.1016/j.paid.2015.05.029.

Festinger, L. (1954). A theory of social comparison processes. Human Relations, 7, 117-140. https://doi. org/10.1177/001872675400700202.

Fiske, S. T. (2011). Envy up, scorn down: How status divides us. New York: Russell Sage Foundation Publications.

Gibbons, F. X., \& Buunk, B. P. (1999). Individual differences in social comparison: Development of a scale of social comparison orientation. Journal of Personality and Social Psychology, 76(1), 129-142. https://doi.org/10.1037//0022-3514.76.1.129.

Gilbert, D. T., Giesler, R. B., \& Morris, K. A. (1995). When comparisons arise. Journal of Personality and Social Psychology, 69(2), 227-236. https://doi.org/10.1037/0022-3514.69.2.227.

Guay, F., Boivin, M., \& Hodges, E. V. E. (1999). Social comparison processes and academic achievement: The dependence of the development of self-evaluations on friends' performance. Journal of Educational Psychology, 91(3), 564-568. https://doi.org/10.1037/0022-0663.91.3.564.

Guimond, S., Branscombe, N. R., Brunot, S., Buunk, A. P., Chatard, A., Désert, M., et al. (2007). Culture, gender, and the self: Variations and impact of social comparison processes. Journal of Personality and Social Psychology, 92(6), 1118-1134. https://doi.org/10.1037/0022-3514.92.6.1118.

Huguet, P., Dumas, F., Marsh, H., Régner, I., Wheeler, L., Suls, J., et al. (2009). Clarifying the role of social comparison in the Big-Fish-Little-Pond effect (BFLPE): An integrative study. Journal of Personality and Social Psychology, 97(1), 156-170. https://doi.org/10.1037/a0015558.

Ireson, J., \& Hallam, S. (2009). Academic self-concepts in adolescence: Relations with achievement and ability grouping in schools. Learning and Instruction, 19(3), 201-213. https://doi.org/10.1016/j. learninstruc.2008.04.001.

Jansen, M., Schroeders, U., Lüdtke, O., \& Marsh, H. W. (2015). Contrast and assimilation effects of dimensional comparisons in five subjects: An extension of the I/E model. Journal of Educational Psychology, 107(4), 1086-1101. https://doi.org/10.1037/edu0000021.

Jiang, Y., \& Kleitman, S. (2015). Metacognition and motivation: Links between confidence, selfprotection and self-enhancement. Learning and Individual Differences, 37, 222-230. https://doi.org/ 10.1016/j.lindif.2014.11.025.

Locke, K. D. (2005). Connecting the horizontal dimension of social comparison with self-worth and selfconfidence. Personality and Social Psychology Bulletin, 31(6), 795-803. https://doi.org/10.1177/ 0146167204271634.

Marsh, H. W. (1991). Failure of high-ability high schools to deliver academic benefits commensurate with their students' ability levels. American Educational Research Journal, 28, 445-480.

Michie, F., Glachan, M., \& Bray, D. (2001). An evaluation of factors influencing the academic selfconcept, self-esteem and academic stress for direct and re-entry students in higher education. Educational Psychology, 21(4), 455-472. https://doi.org/10.1080/01443410120090830.

Müller-Kalthoff, H., Helm, F., \& Möller, J. (2017). The big three of comparative judgment: On the effects of social, temporal, and dimensional comparisons on academic self-concept. Social Psychology of Education, 20(4), 849-873. https://doi.org/10.1007/s11218-017-9395-9.

Mussweiler, T., Ruter, K., \& Epstude, K. (2004). The man who wasn't there: Subliminal social comparison standards influence self-evaluation. Journal of Experimental Social Psychology, 40(5), 689-696. https://doi.org/10.1016/j.jesp.2004.01.004.

Pulford, B. D., \& Sohal, H. (2006). The influence of personality on HE Students' confidence in their academic abilities. Personality and Individual Differences, 41, 1409-1419. https://doi.org/10.1016/j. paid.2006.05.010.

Sander, P., \& Sanders, L. (2006). Understanding academic confidence. Psychology Teaching Review, 12(1), 31-44.

Sander, P., \& Sanders, L. (2009). Measuring academic behavioural confidence: The ABC scale revisited. Studies in Higher Education, 34, 19-35. https://doi.org/10.1080/03075070802457058.

Stankov, L., Lee, J., Luo, W., \& Hogan, D. J. (2012). Confidence: A better predictor of academic achievement than self-efficacy, self-concept and anxiety? Learning and Individual Differences, 22(6), 747-758. https://doi.org/10.1016/j.lindif.2012.05.013. 
Steffens, M. C., Jelenec, P., \& Noack, P. (2010). On the leaky math pipeline: Comparing implicit mathgender stereotypes and math withdrawal in female and male children and adolescents. Journal of Educational Psychology, 102(4), 947-963. https://doi.org/10.1037/a0019920.

Strickhouser, J. E., \& Zell, E. (2015). Self-evaluative effects of dimensional and social comparison. Journal of Experimental Social Psychology, 59, 60-66. https://doi.org/10.1016/j.jesp.2015.03.001.

Suls, J., \& Wheeler, L. (2000). Handbook of social comparison: Theory and research. Dordrecht: Kluwer Academic Publishers.

Trautwein, U., Lüdtke, O., Marsh, H. W., \& Nagy, G. (2009). Within-school social comparison: How students perceive the standing of their class predicts academic self-concept. Journal of Educational Psychology, 101(4), 853-866. https://doi.org/10.1037/a0016306.

Vogel, E. A., Rose, J. P., Okdie, B. M., Eckles, K., \& Franz, B. (2015). Who compares and despairs? The effect of social comparison orientation on social media use and its outcomes. Personality and Individual Differences, 86, 249-256. https://doi.org/10.1016/j.paid.2015.06.026.

Wehrens, M. J. P. W. (2008). How did YOU do? Social comparison in secondary education. PhD Thesis, University of Groningen.

Wehrens, M. J. P. W., Kuyper, H., Dijkstra, P., Buunk, A. P., \& Van Der Werf, M. P. C. (2010). The longterm effect of social comparison on academic performance. European Journal of Social Psychology, 40(7), 1158-1171. https://doi.org/10.1002/ejsp.706.

Briony D. Pulford is an Associate Professor of Psychology at the University of Leicester and head of the Leicester Judgment and Decision Making Group. Her research covers topics such as the communication of confidence, cooperation, ambiguity aversion, game theory, and individual differences.

Bethan Woodward graduated from the University of Leicester in 2010, with a BSc in Psychology. She now lives in Perth, Western Australia with her partner, works as an Executive Assistant, and still has a keen interest in Social Psychology.

Eve Taylor graduated from the University of Leicester with a BSc in Psychology with Cognitive Neuroscience. She is about to pursue an MSc is Addiction studies at Kings College London. 